\title{
Effect of Radiation on Boundary Layer Flow and Heat Transfer over a Stretching Sheet in the Presence of Free Stream Velocity
}

\author{
B. J. Gireesha ${ }^{\dagger}$, S. Manjunatha and C. S. Bagewadi \\ ${ }^{1}$ Department of Studies and Research in Mathematics, Kuvempu University, Shankaraghatta, Karnataka, 577 451, \\ India \\ †Corresponding Author Email: bjgireesu@ rediffmail.com
}

(Received September 20, 2012; accepted March 27, 2013)

\begin{abstract}
Aim of the paper is to study an unsteady boundary layer flow and heat transfer analysis of a viscous, incompressible dusty fluid over a porous stretching surface in the presence of time dependent free stream. The governing partial differential equations are reduced to couple non-linear ordinary differential equations by similarity transformation. Numerical solutions of these equations are obtained by using RKF-45 method. The solution obtained is dependent on governing parameters like magnetic parameter, unsteadiness parameter, Prandtl number, dust interaction parameter, suction parameter, Eckert number, the ratio of free stream velocity parameter and stretching parameter and thermal radiation parameter. Some important findings reported in this work reveals that the effect of radiation have significant impact in controlling the rate of heat transfer in the boundary layer region.
\end{abstract}

Keywords: Unsteady flow and heat transfer, Boundary layer flow, Stretching porous surface, Dusty fluid, Numerical solution, Free stream velocity.

\section{NOMENCLATURE}

\begin{tabular}{|c|c|c|c|}
\hline$A=\frac{\alpha}{c}$ & unsteady parameter & $l=\frac{m n}{\rho_{p}}$ & mass concentration \\
\hline$a_{1}=\frac{1}{\tau_{T} \rho c}(1-\sigma t)$ & $\begin{array}{l}\text { local fluid particle interaction } \\
\text { parameters for heat }\end{array}$ & $M=\frac{\sigma \boldsymbol{B}_{0}^{2}}{\rho c}(1-\alpha t)$ & magnetic parameter \\
\hline$a_{2}=\frac{1}{\tau_{v} \rho v}(1-\alpha t)$ & $\begin{array}{l}\text { local fluid particle is local fluid } \\
\text { particle interaction parameter of } \\
\text { velocity. }\end{array}$ & $N$ & number of dust particals \\
\hline$B_{0}$ & induced magnetic field & $N r=\frac{16 \sigma^{*} T^{3}}{3 k_{1} k^{*}}$ & thermal radiative parameter \\
\hline$b_{1}=\frac{c_{p}}{\tau_{T} c_{m} c}(1-\alpha t)$ & $\begin{array}{l}\text { local fluid particle interaction } \\
\text { parameters for heat transfer }\end{array}$ & $\operatorname{Pr}=\frac{\mu c}{k^{*}}$ & Prandtl number \\
\hline$c$ & $\begin{array}{l}\text { stretching rate being a positive } \\
\text { constant }\end{array}$ & $q_{r}$ & radiative heat flux \\
\hline$c_{m}$ & specific heat of dust phase & $R=\frac{v_{0}}{\sqrt{v c}}$ & suction parameter \\
\hline$c_{p}$ & specific heat of fluid phase & $\left(T, T_{p}\right)$ & $\begin{array}{l}\text { temperature of the fluid and dust } \\
\text { Particle }\end{array}$ \\
\hline$E c=\frac{v^{2}}{c_{p} T_{0}}$ & Eckert number & $T_{w}$ & temperature of the wall \\
\hline$k^{*}$ & thermal conductivity & $T_{\infty}$ & $\begin{array}{l}\text { constant temperature far away from } \\
\text { the sheet. }\end{array}$ \\
\hline$k_{1}$ & mean absorption coefficient & $(u, v)$ & the velocity components of the fluid \\
\hline
\end{tabular}




$\begin{array}{ll}\left(u_{p}, v_{p}\right) & \begin{array}{l}\text { the velocity components of the } \\ \text { particle phase along the } \mathrm{x}-\text { and } \mathrm{y} \text {-axis }\end{array} \\ U(x, t)=\frac{b x}{1-\alpha t} & \begin{array}{l}\text { free stream velocity of the fluid } \\ u_{w}(x, t)=\frac{c x}{1-\alpha t}\end{array} \\ v_{w}=-\frac{v_{0}}{\sqrt{1-\alpha t}} & \text { velocity of sheet }\end{array}$

\section{INTRODUCTION}

Sakiadis (1961) initiated the study of the boundary layer flow over a stretched surface moving with a constant velocity and formulated a boundary-layer equation for two-dimensional and axisymmetric flows. He employed a similarity transformation and obtained the numerical solution for problem. Tsou et al. (1967) analyzed the effect of heat transfer in the boundary layer on a continuous moving surface with a constant velocity and experimentally confirmed the numerical results of Sakiadis (1961). This interest stems from the fact that Momentum and heat transfer of boundary layer flow over a stretching sheet have been applied in many chemical engineering processes like metallurgical process, polymer extrusion process involving cooling of a molten liquid being stretched into a cooling system. The fluid mechanical properties desired for an outcome of such a process would mainly depend on two aspects, one is the cooling liquid used and the other is the rate of stretching. The rate of cooling and the desired properties of the end product can be controlled by the use of electrically conducting fluid and application of magnetic fields. The use of magnetic field has been used in the process of purification of molten metal from nonmetallic inclusions. In addition, due to the significance of the study of flow heat transfer caused by a stretching surface in many practical manufacturing process such as drawing, annealing and tinning of copper wires, continuous stretching, rolling and manufacturing of plastic films and artificial fibers, heat treated materials traveling on conveyer belts, glass blowing, crystal growing, paper production and so on.

Carragher et al. (1982) investigated the flow and heat transfer over a stretching surface when the temperature difference between the surface and an ambient fluid is proportional to a power of distance from a fixed point. Vajravelu et al. (1992) discussed hydromagnetic flow of a dusty fluid over a stretching sheet. Sharidan (2006) studied similarity solutions for unsteady boundary layer flow and heat transfer due to a stretching sheet. Elbashbeshy et al. (2010) have studied the effects of thermal radiation and magnetic field on an unsteady mixed convection flow and heat transfer over a porous stretching surface. Subhas Abel et al. (2008) discussed the heat transfer in MHD viscoelastic fluid flow over a stretching sheet with the effects of variable thermal conductivity, non-uniform heat source and radiation. Grubka et al. (1985) studied the temperature field in the flow over a stretching surface when subjected to a uniform heat flux. Andersson et al. (2000) presented a new similarity solution for the temperature fields, which transforms the time-dependent thermal energy equation to an ordinary differential equation. Aziz (2009) phase along the $\mathrm{x}$ - and $\mathrm{y}$-axis positive constant which measures the unsteadiness

$$
\begin{array}{ll}
\beta=\frac{1}{\tau c}(1-\alpha t) & \text { fluid particle interaction parameter } \\
\lambda=\frac{b}{c} \infty & \text { free stream velocity parameter } \\
\mu & \text { viscosity of the fluid }
\end{array}
$$

obtained the numerical solution for laminar thermal boundary over a flat plate with a convective surface boundary condition using the symbolic algebra software Maple. Ali et al. (2010) studied an unsteady flow and heat transfer past an axisymmetric permeable shrinking sheet with radiation effect. Pop et al. (2004) have studied Radiation Effect on flow near the stagnation point. Mustafa et al. (2008) have obtained solutions for an unsteady MHD memory flow with oscillatory suction, variable free stream and heat source. Sharma et al. (2009) obtained the results for the effects of variable thermal conductivity and heat source/sink on MHD flow near a stagnation point on a linearly stretching sheet. The governing similarity equations contain Prandtl number, Eckret number, number density and unsteadiness parameter. Although a similarity solution is accomplished by these authors, some physically unrealistic phenomena are encountered for specific values of the unsteadiness parameter.

The present analysis concern with the investigation of two dimensional unsteady flow and heat transfer of a viscous incompressible dusty fluid about stagnation point on permeable stretching sheet in the presence of time dependent free stream velocity with radiation effect. Further, both the variable wall temperature (VWT) and variable heat flux (VHF) conditions have been considered. The governing equations are solved numerically using RKF-45 method with the help of symbolic algebra software Maple.

\section{Mathematical Formulation AND SOLUTION OF THE PROBLEM}

Consider the two-dimensional unsteady boundary layer flow of a dusty viscous and incompressible fluid (with electric conductivity $\sigma_{0}$ ) in a stagnation point on stretching sheet in the presence of time dependent free stream. The fluid occupies the upper half plane i.e. y > 0 . The flow is considered to be generated by stretching of an elastic boundary sheet from a slit with the application of two equal and opposite forces in such way that velocity of boundary sheet is quadratic order of the flow directional coordinate $\mathrm{x}$. A uniform magnetic field $B_{0}$ is imposed along the y-axis.

Two-dimensional boundary layer equations of dusty fluid in usual notation are:

$$
\frac{\partial u}{\partial x}+\frac{\partial v}{\partial y}=0
$$




$$
\begin{aligned}
& \frac{\partial u}{\partial t}+u \frac{\partial u}{\partial x}+v \frac{\partial u}{\partial y}=u \frac{\partial U}{\partial x}+\frac{\partial U}{\partial t}+ \\
& \frac{K N}{\rho}\left(u_{p}-u\right)+\frac{\mu}{\rho} \frac{\partial^{2} u}{\partial y^{2}}-\frac{\sigma B_{0}^{2}}{\rho}(u-U) \\
& \frac{\partial u_{p}}{\partial t}+u_{p} \frac{\partial u_{p}}{\partial x}+v_{p} \frac{\partial u_{p}}{\partial y}=\frac{K}{m}\left(u-u_{p}\right) \\
& \frac{\partial v_{p}}{\partial t}+u_{p} \frac{\partial v_{p}}{\partial x}+v_{p} \frac{\partial v_{p}}{\partial y}=\frac{K}{m}\left(v-V_{p}\right) \\
& \frac{\partial\left(\rho_{p} u_{p}\right)}{\partial x}+\frac{\partial\left(\rho_{p} v_{p}\right)}{\partial y}=0
\end{aligned}
$$

In deriving these equations, the Stokesian drag force is considered for the interaction between the fluid and particle phase and the induced magnetic field is neglected. It is also assumed that the external electric field is zero and the electric field due to polarization of charges is negligible.

$$
\begin{aligned}
& u=u_{w}(x, t), \quad v=v_{w}(x, t), \text { at } y=0, \\
& u \rightarrow U_{w}(x, t), \quad u_{p} \rightarrow U_{w}(x, t) \\
& v_{p} \rightarrow v, \quad \rho_{p} \rightarrow k_{p} \quad \text { as } y \rightarrow \infty,
\end{aligned}
$$

Equations (1) to (5) subjected to boundary conditions Eq. (6) admit self-similar solution in terms of the similarity function $\mathrm{f}$ and the similarity variable $\eta$ and defined by

$$
\begin{array}{ll}
u=\frac{c x}{1-\alpha t} f^{\prime}(\eta), & v=-\sqrt{\frac{c v}{1-\alpha t} f(\eta)} \\
u=\frac{c x}{1-\alpha t} F(n), & v_{p}=-\sqrt{\frac{c v}{1-\alpha t} G(\eta)} \\
\eta=\sqrt{\frac{c}{v(1-\alpha t)} y,} & \rho_{r}=H(\eta)
\end{array}
$$

where a prime denotes the differentiation with respect to $\eta$. Substituting the set of Eq. (7) into Eqs. (1) to (5) gives

$$
\begin{gathered}
f^{\prime \prime \prime}(\eta)+f(\eta) f^{\prime \prime}(\eta)-f^{\prime}(\eta)^{2}-A\left[f^{\prime}(\eta)\right. \\
\left.+\frac{\eta}{2} f^{\prime \prime}(\eta)\right]+l \beta H\left[F(\eta)-f^{\prime}(\eta)\right] \\
-M\left(f^{\prime}(\eta)-\lambda\right)+A \lambda+\lambda^{2}=0, \\
A\left[F(\eta)+\frac{\eta}{2} F^{\prime}(\eta)\right]+G(\eta) F^{\prime}(\eta) \\
+F(\eta)^{2}+\beta\left[f(\eta)-f^{\prime}(\eta)\right]=0,
\end{gathered}
$$

$$
\begin{aligned}
& \frac{A}{2}\left[G(\eta)+\frac{\eta}{2} G^{\prime}(\eta)\right]+G(\eta) G^{\prime}(\eta) \\
& +\beta[f(\eta)+G(\eta)]=0, \\
& H(\eta) F(\eta)+G^{\prime}(\eta) H(\eta)+G(\eta) H^{\prime}(\eta)=0 .
\end{aligned}
$$

The corresponding boundary conditions are transformed to:

$$
\begin{array}{ll}
f^{\prime}(\eta)=1, & f(\eta)=R \quad \text { at } \quad \eta=0 \\
f^{\prime}(\eta)=\lambda, \quad F(\eta)=\lambda, & G(\infty)=-f(\eta), \\
H(\eta)=E, & \text { as } \eta \rightarrow \infty,
\end{array}
$$

If $A=0$ and $\lambda=0$, the analytical and numerical solutions of Eqs. (1) to (5) was given by Vajravelu and Nayfeh (1992).

\section{Heat TranSFER AND ANALYSES}

The boundary layer heat transport equations in the presence of thermal radiation in space for two dimensional flows are given by

$$
\begin{gathered}
\rho c_{p}\left[\frac{\partial T}{\partial t}+u \frac{\partial T}{\partial x}+v \frac{\partial T}{\partial y}\right]=k * \frac{\partial^{2} T}{\partial y^{2}}+ \\
\frac{N c_{p}}{\tau_{T}}\left(T_{p}-T\right)+\frac{N}{\tau_{v}}\left(u_{p}-u\right)^{2}-\frac{\partial q_{r}}{\partial y}, \\
N c_{m}\left[\frac{\partial T_{p}}{\partial t}+u_{p} \frac{\partial T_{p}}{\partial x}+v_{p} \frac{\partial T_{p}}{\partial y}\right] \\
=-\frac{N c_{p}}{\tau_{T}}\left(T_{p}-T\right) .
\end{gathered}
$$

The Rosseland approximation Eq. (12), i.e., the irradiative heat flux $q_{r}$ is modeled as

$$
q_{r}=-\frac{4 \sigma^{*}}{3 k_{1}} \frac{\partial T^{4}}{\partial y}
$$

Assuming that the differences in the temperature within the flow are such that the term $T^{4}$ can be expressed as linear combination of the temperature, we expand $T^{4}$ in a Taylor's series about $T_{\infty}$ as follows

$T_{4}=T_{\infty}^{4}+4 T_{\infty}^{3}\left(T-T_{\infty}\right)+6 T_{\infty}^{2}\left(T-T_{\infty}\right)^{2}+\cdots$

and neglecting higher order terms beyond the first degree in $\left(T-T_{\infty}\right)$, we get

$T^{4} \cong-3 T^{4} \infty+4 T_{\infty}^{3} T$.

Substituting Eq. (17) in Eq. (15) we obtain 


$$
\frac{\partial q_{r}}{\partial y}=-\frac{16 T_{\infty}^{4}}{3 k_{1}} \frac{\partial^{2} T}{\partial y^{2}} .
$$

The solution of Eq. (13) to Eq. (14) depends on the nature of the prescribed boundary condition. Here, the two types of heating processes are discussed.

\subsection{Variable wall temperature (VWT)}

For this heating process, the variable wall temperature is assumed to be a quadratic function of $x$ and it is given by

$$
T=T_{w}=T_{\infty}+T_{0}\left(\frac{c x^{2}}{v}\right)(1-\alpha t)^{-2} \text { at } y=0
$$

$T \rightarrow T_{\infty}, \quad T_{p} \rightarrow T_{\infty} \quad$ as $\quad y \rightarrow \infty$,

In order to obtain similarity solution for the temperatures $\theta(\eta)$ and $\theta_{p}(\eta)$ we define dimensionless temperature variables as:

$$
\theta(\eta)=\frac{T-T_{\infty}}{T_{w}-T_{\infty}}, \quad \theta_{p}(\eta)=\frac{T_{p}-T_{\infty}}{T_{w}-T_{\infty}},
$$

where $T-T_{\infty}=T_{9}\left(\frac{c x^{2}}{v}\right)(1-\alpha t)^{-2} \theta(\eta)$.

Using Eq. (18), Eq. (19) and Eq. (20) in the Eq. (13) and Eq. (14), we get

$$
\begin{aligned}
& (1+N r) \theta^{\prime \prime}(\eta)+\operatorname{Pr}\left[f(\eta) \theta^{\prime}(\eta)\right. \\
& \left.-2 f^{\prime}(\eta) \theta(\eta)\right]-\frac{A}{2} \operatorname{Pr}\left[4 \theta(\eta)+\eta \theta^{\prime}(\eta)\right] \\
& +N \operatorname{Pr} a_{1}\left[\theta_{p}(\eta)-\theta(\eta)\right] \\
& +N \operatorname{Pr} E c a_{2}[F(\eta)-f(\eta)]^{2}=0, \\
& G(\eta) \theta_{p}^{\prime}(\eta)+2 F(\eta) \theta_{p}(\eta)+\frac{A}{2}\left[4 \theta_{p}(\eta)\right. \\
& \left.+\eta \theta^{\prime}(\eta)\right]+b_{1}\left[\theta_{p}(\eta)-\theta(\eta)\right]=0,
\end{aligned}
$$

Using the Eq. (19) and Eq. (20), the corresponding boundary conditions for $\theta(\eta)$ and $\theta_{p}(\eta)$ reduces to the following form

$$
\begin{aligned}
& \theta(\eta)=1 \quad \text { at } \quad \eta=0, \\
& \theta(\eta) \rightarrow 0, \quad \theta_{p}(\eta) \rightarrow 0 \quad \text { as } \quad \eta \rightarrow \infty
\end{aligned}
$$

\subsection{Variable heat flux (VHF)}

For this heating process, employ the following variable heat flux boundary conditions,

$$
\begin{aligned}
& \frac{\partial T}{\partial y}=-\frac{q_{w}(x, t)}{k^{*}} \text { at } \quad y=0, \\
& T \rightarrow T_{\infty}, \quad T_{p} \rightarrow T_{\infty} \quad \text { as } \quad y \rightarrow \infty,
\end{aligned}
$$

where $q_{w}(x, t)=q_{w} 0^{2}\left(\frac{c}{v}\right)^{\frac{3}{2}}(1-\alpha t)^{-\frac{5}{2}}$.

In order to obtain similarity solution for temperature, define the dimensionless temperature variables in VHF case as in Eq. (20) where as $T_{w}-T_{\infty}=\frac{q w_{0}}{k^{*}}\left[\frac{\alpha^{2}}{v(1-\alpha t)^{2}}\right] \theta(\eta)$.

Using dimensionless variable Eq. (20), the temperature Eq. (13) and Eq. (14) take the form

$(1+N r) \theta^{\prime \prime}(\eta)+\operatorname{Pr}\left[f(\eta) \theta^{\prime}(\eta)\right.$

$\left.-2 f^{\prime}(\eta) \theta(\eta)\right]-\frac{A}{2} \operatorname{Pr}\left[4 \theta(\eta)+\eta \theta^{\prime}(\eta)\right]$

$+N \operatorname{Pr} a_{1}\left[\theta_{p}(\eta)-\theta(\eta)\right]$

$+N \operatorname{Pr} E c a_{2}[F(\eta)-f(\eta)]^{2}=0$,

$G(\eta) \theta_{p}^{\prime}(\eta)+2 F(\eta) \theta_{p}(\eta)+\frac{A}{2}\left[4 \theta_{p}(\eta)\right.$

$\left.+\eta \theta^{\prime}(\eta)\right]+b_{1}\left[\theta_{p}(\eta)-\theta(\eta)\right]=0$,

The corresponding boundary conditions become

$\theta^{\prime}(\eta)=-1$ at $\eta=0$

$\theta(\eta)=0, \theta_{p}(\eta)=0$ as $\eta \rightarrow \infty$.

The physical quantities of interest in this problem are the skin friction coefficient $C_{f}$ and the local Nusselt number $N u_{x}$, which are defined as

$C_{f}=\frac{\varsigma_{w}}{\rho U^{2}{ }_{w}}, \quad N u_{x}=\frac{x q_{w}}{k\left(T_{w}-T_{\infty}\right)}$,

where the skin friction $\tau_{w}$ and the heat transfer from the sheet $q_{w}$ are given by

$\tau_{w}=\mu\left(\frac{\partial u}{\partial y}\right)_{y=0}, \quad q_{w}=-k\left(\frac{\partial T}{\partial y}\right)_{y=0}$,

Using the non-dimensional variables, we obtain

$C f \operatorname{Re}_{x}{ }^{1 / 2}=f^{\prime \prime}=0$,

$N u_{x} / \operatorname{Re}_{x} 1 / 2=-\theta^{\prime}(0)(V W T$ case $)$,

$N u_{x} / \operatorname{Re}_{x} 1 / 2=\frac{1}{\theta(0)}($ VHF case $)$. 


\section{NuMERical SOLUTIONS}

Equations (8) to (11) together with the boundary conditions Eq. (12) form a nonlinear coupled boundary value problem, which has been solved numerically using a very efficient Runge Kutta Fehlberg fourth-fifth order method (RKF45 Method), which was discussed by Aziz (2009). In this method it is most important to choose the appropriate finite values of $\eta \rightarrow \infty$. Here in our calculation process we take $\eta \rightarrow 5$. The accuracy of this numerical method was validated for the case of (VWT) by a direct comparison with the numerical results reported by Pop et al. (2004) and Phool Singh et al. (2010) for the steady state flow case $(A=0)$ and $(N r=E c=0)$. Table 1 represents results of this comparison for $f^{\prime \prime}(0)$. It is observed from this table that a very good agreement achieved between the results.

Table 1 Comparison of the values of $f^{\prime \prime}(0)$ for different values of stretching parameter $\lambda$ when

\begin{tabular}{|c|c|c|c|}
\hline \multicolumn{4}{c}{$A=E c=M=R=N=0$ and $N r=1$} \\
\hline$\lambda$ & $\begin{array}{c}\text { Pop et.al. } \\
(2004)\end{array}$ & $\begin{array}{c}\text { Phool } \\
\text { Singh } \text { et.al. } \\
(2010)\end{array}$ & $\begin{array}{c}\text { Present } \\
\text { Study }\end{array}$ \\
\hline 0.1 & -0.9694 & -0.9696 & -0.9696 \\
\hline 0.2 & -0.9181 & -0.9181 & -0.9181 \\
\hline 0.5 & -0.6673 & -0.6672 & -0.6672 \\
\hline 2.0 & 2.0174 & 2.0173 & 2.0170 \\
\hline 3.0 & 4.7290 & 4.7290 & 4.7290 \\
\hline
\end{tabular}

\section{RESUltS AND DISCUSSION}

An unsteady boundary layer flow and heat transfer of a dusty incompressible fluid over a stretching sheet in the presence of free stream velocity and thermal radiation effect is examined in this paper. The boundary layer equations of momentum and heat transfer are solved numerically. The temperature profile $\theta(\eta)$ in VWT and VHF case depicted graphically. The numerical solutions are obtained for various values of the governing parameters such as $A, M, R . \beta, p r, \lambda, E c \quad$ and $N r$. Figures 1(a), 1(b), and 1(c) represent horizontal velocity profile of both fluid and dust particles for various value of $A$ when $\operatorname{Pr}=0.71, R=0, \quad M=0.1$, $N=0.2, N r=1, \beta=0.1$, and $\lambda=0.5,2.0,1.0$ One can observe from the Figs. 1(a) and 1(b) that the velocity decreases with the increase of the unsteady parameter $\mathrm{A}$ for all values of $\lambda$. At $\lambda>1$ there is an formation of inverted boundary layer. At $\lambda=1$, there would be no formation of boundary layer, as the fluid velocity is equal to the surface velocity. It is interesting to note that the thickness of boundary deceases with increasing values of $A$ and $\lambda$.

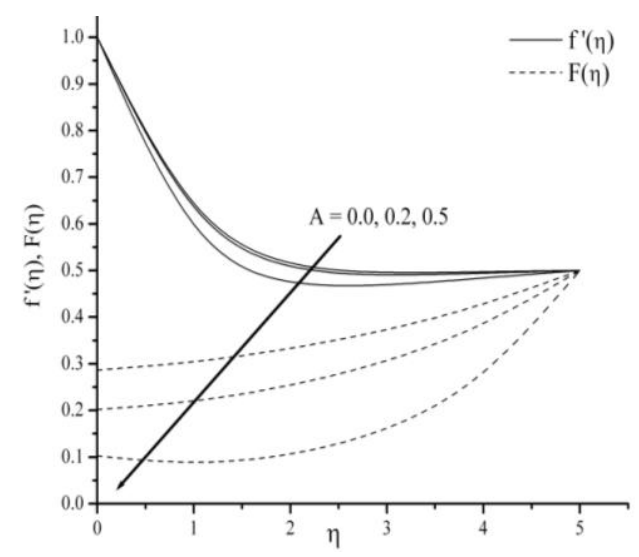

Fig. 1(a). Effect of unsteady parameter $A$ for fluid and dust phase velocities when $\operatorname{Pr}=0.71, R=2$, $M=0.1, N=0.2, N r=1$ and $\beta=0.1 \lambda=0.5$.

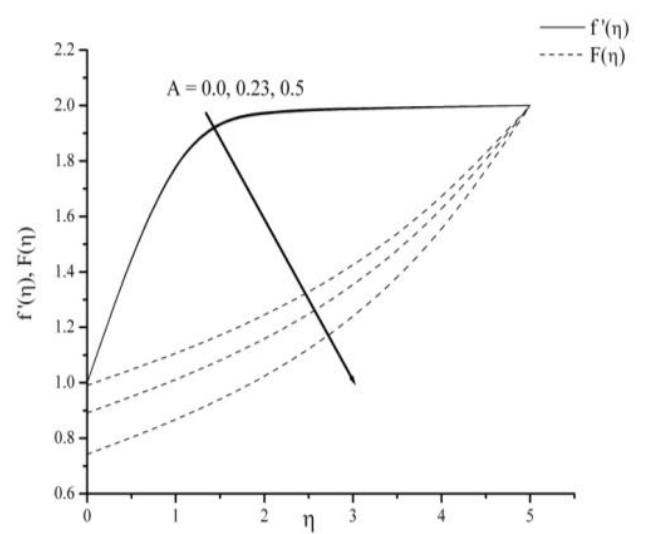

Fig. 1(b). Effect of unsteady parameter $A$ for fluid and dust phase velocities when $\operatorname{Pr}=0.71, R=2$, $M=0.1, N=0.2, N r=1$ and $\beta=0.1 \lambda=2.0$.

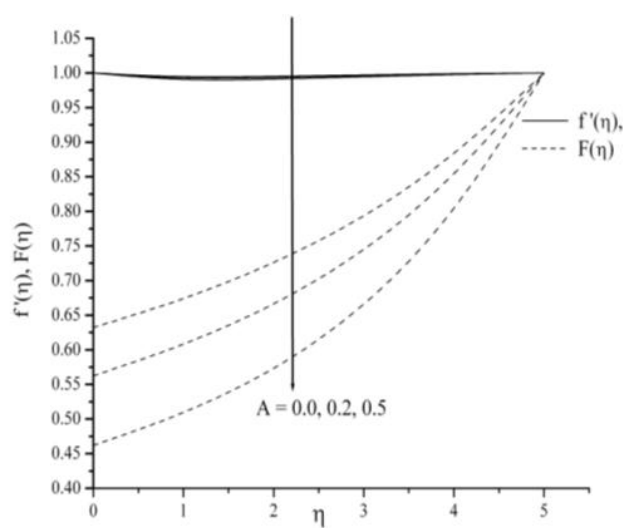

Fig. 1(c). Effect of unsteady parameter $A$ for fluid and dust phase velocities when $\operatorname{Pr}=0.71, R=2$, $M=0.1, N=0.2, N r=1$ and $\beta=0.1 \lambda=1.0$.

The magnetic parameter $M$ represents the impact of magnetic field on the flow. The presence of Lorentz force retards the force on the velocity field and therefore as $M$ increases velocity decreases. This is shown in Fig. 2(a) when $\lambda<1$. In case when $\lambda>1$. which is just opposite of $\lambda<1$, as expected the velocity profile increases with the increase in the $M$ as shown Fig. 2(b). 


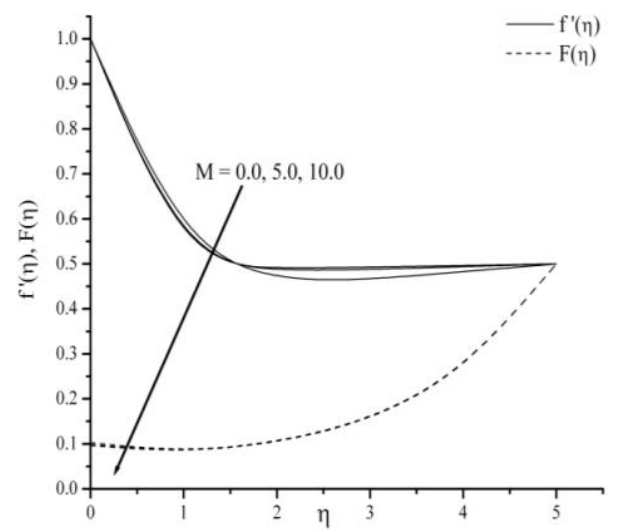

Fig. 2(a). Effect of Hartman number $M$ for fluid and dust phase velocities when $\operatorname{Pr}=0.71, R=2$, $A=0.5, N=0.2, N r=1$ and $\beta=0.1, \lambda=0.5$.

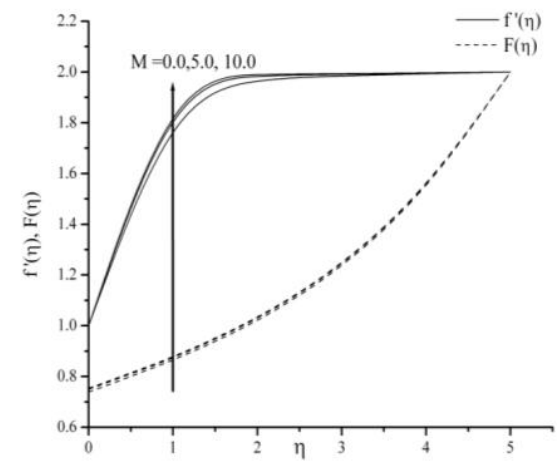

Fig. 2(b). Effect of Hartman number $M$ for fluid and dust phase velocities when $\operatorname{Pr}=0.71, R=0$, $A=0.5, N=0.2, N r=1$ and $\beta=0.1, \lambda=2$.

It is observed from the Table 2 that the skin friction decreases as unsteady parameter increase for $\lambda<1$. Here the negative value of $f^{\prime \prime}(0)$ means the solid surface exerts a drag force on the fluid. This is due to the development of the velocity boundary layer is caused solely on the stretching plate. For $\lambda>1$, skin friction increases as unsteady parameter increase, this is due to fact that inverted boundary layer formed. Nusselt number decreases with increase in unsteady parameter for both VWT and VHF case.

Figures 3(a) and 3(b) are the graphical representation for temperature distribution of VWT and VHF case, for different values of unsteady parameter $A$ versus $\eta$ when $\lambda=0.5$. It is evident that temperature of fluid and dust particle decreases with the increase of unsteady parameter $A$. Temperature at a point of surface decreases significantly with the increase of $A$ i.e. rate of heat transfer increases with increasing unsteady parameter $A$.

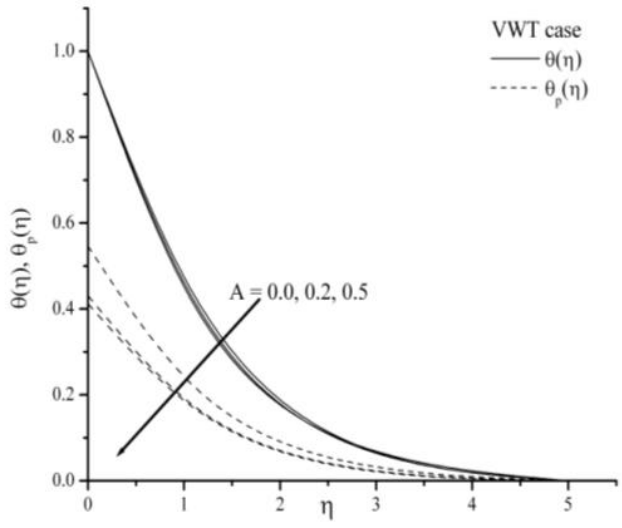

Fig. 3(a). Effect of unsteady parameter $A$ on temperature distribution with $\operatorname{Pr}=0.71, E c=1$, $R=2, N=0.2, \beta=0.1, N r=1$ when $\lambda=0.5$.

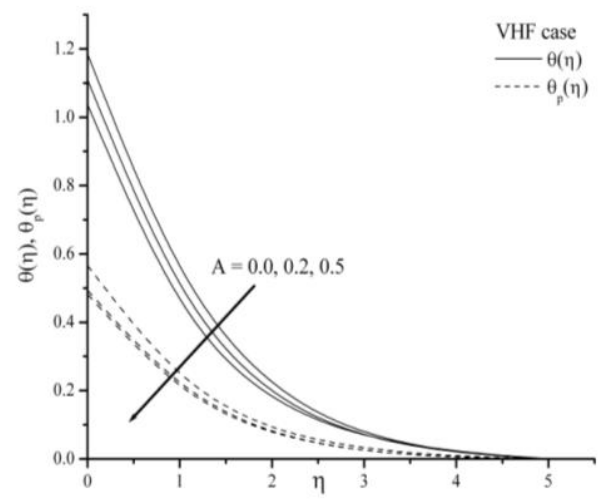

Fig. 3(b). Effect of unsteady parameter $A$ on temperature distribution with $\operatorname{Pr}=0.71, E c=1$, $R=2, N=0.2, \beta=0.1, N r=1$ when $\lambda=0.5$

Figures 4(a) and 4(b) represent the temperature distribution for VWT and VHF case, for different values of unsteady parameter $A$ versus $\eta$ when $\lambda=2.0$. It shows that the temperature of fluid and dust particle increases with the increase of unsteady parameter $A$, due to formation of invert boundary layer. Thermal boundary layer thickness decreases with the increase in $A$ and $\lambda$.

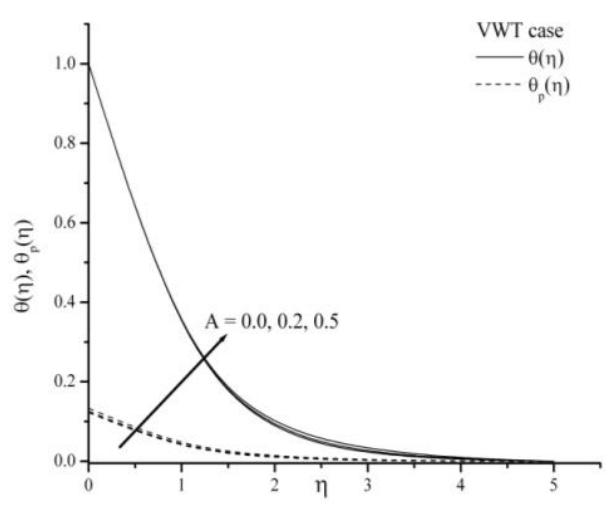

Fig. 4(a). Effect of unsteady parameter $A$ on temperature distribution with $\operatorname{Pr}=0.71, E c=1$, $R=2, N=0.2, \beta=0.1, N r=1$ when $\lambda=2$. 


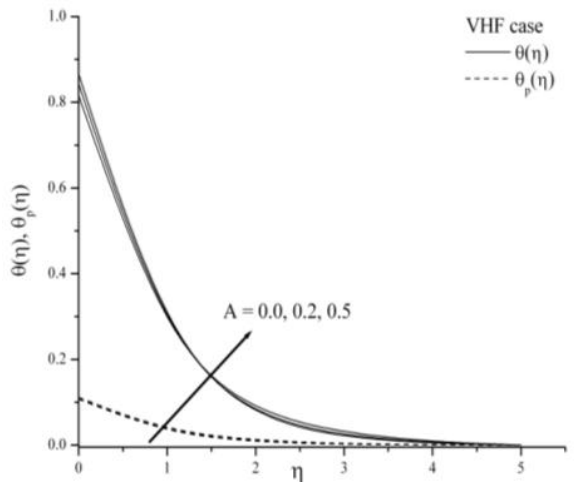

Fig. 4(b). Effect of unsteady parameter $A$ on temperature distribution with $\operatorname{Pr}=0.71, E c=1$, $R=2, N=0.2, \beta=0.1, N r=1$ when $\lambda=2$.

Figures 5(a) and 5(b) depict temperature profiles of $\theta(\eta)$ and $\theta_{p}(\eta)$ versus $\eta$, for different values of Pr. We infer from these figures that temperature of fluid and dust particles decreases with the increase in Pr which implies momentum boundary layer is thicker than the thermal boundary layer. The temperature in both VWT and VHF cases asymptotically approaches to zero in the free stream region.

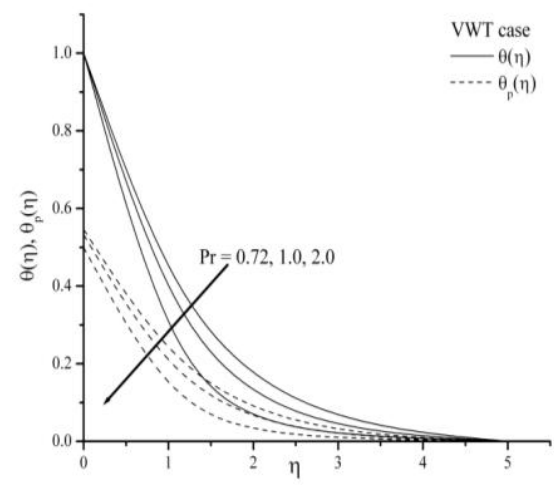

Fig. 5(a). Effect of Prandtl number Pr on temperature distribution with $A=0.5, E c=1$,

$R=2, N=0.2, \beta=0.1, N r=1, \lambda=0.5$

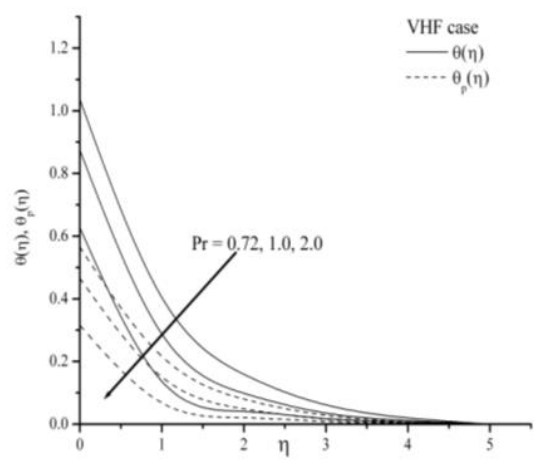

Fig. 5(b). Effect of Prandtl number Pr on temperature distribution with $A=0.5, E c=1$,

$R=2, N=0.2, \beta=0.1, N r=1, \lambda=0.5$
Figures 6(a) and 6(b) indicate the temperature profile of $\theta(\eta)$ and $\theta_{p}(\eta)$ versus $\eta$, for VWT and VHF cases respectively. Here the effect of increasing values of $E c$ is to enhance the temperature of fluid and dust particles at any point which is true for both the cases VWT and VHF. This is due to fact that the heat energy is stored in the considered liquid due to frictional heating.

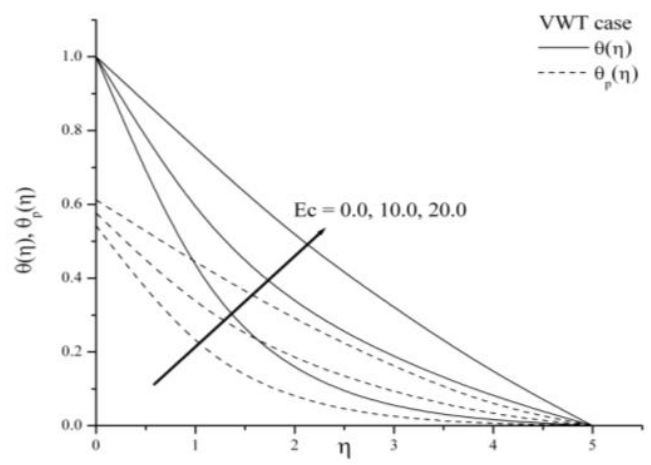

Fig. 6(a). Effect of Eckert number $E c$ on temperature distribution with $A=0.5, \operatorname{Pr}=0.71$, $R=0, N=0.2, \beta=0.1, N r=1, \lambda=0.5$.

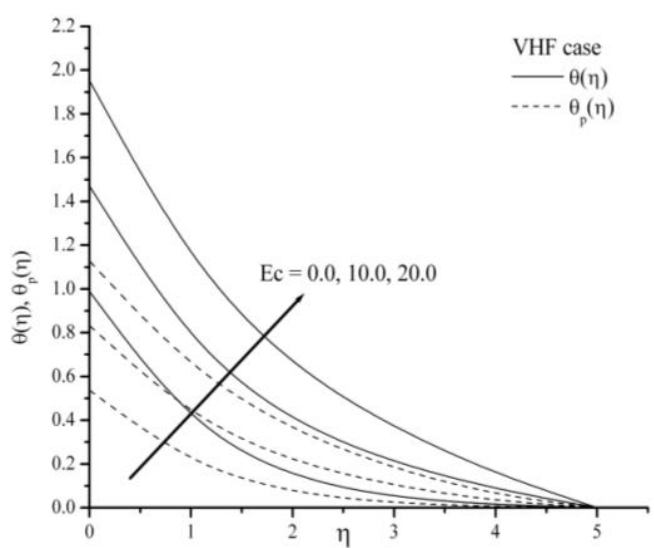

Fig. 6(b). Effect of Eckert number $E c$ on temperature distribution with $A=0.5, \operatorname{Pr}=0.71$, $R=0, N=0.2, \beta=0.1, N r=1, \lambda=0.5$.

Figures 7(a) and 7(b) represent the temperature profile for various values of thermal radiation parameter $\mathrm{Nr}$ in case VWT and VHF respectively. The effect of radiation is also to intensify the heat transfer. Thus the radiation should be at its minimum in order to facilitate the cooling process. This is agreement with the physical fact that the thermal boundary layer thickness increases with increasing $N r$. 


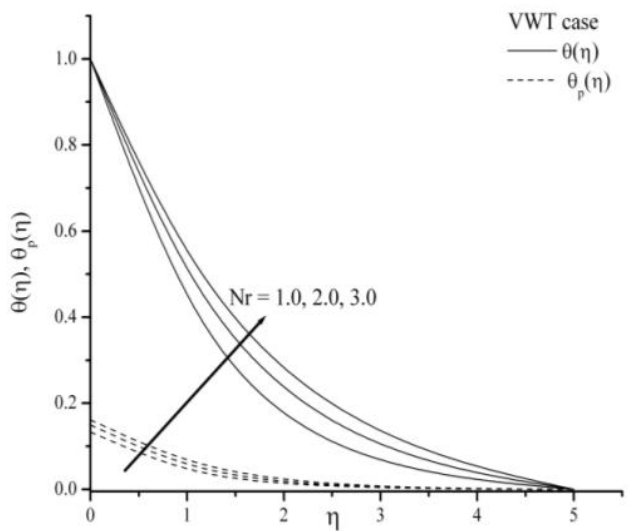

Fig. 7(a). Effect of thermal radiation parameter $\mathrm{Nr}$ on temperature distribution with $\operatorname{Pr}=0.7$ $A=0.5,1, R=0, E c=1, \beta=0.1, \lambda=0.5$.

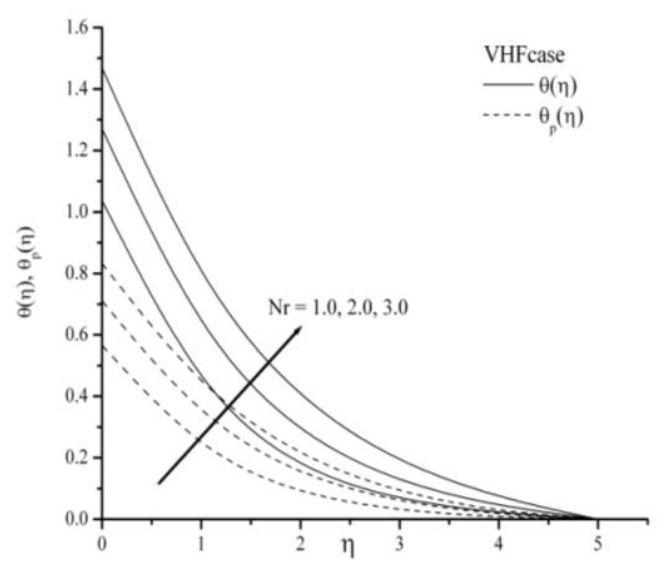

Fig. 7(b). Effect of thermal radiation parameter $\mathrm{Nr}$ on temperature distribution with $A=0.5$, $\operatorname{Pr}=0.71, R=0, E c=1, \beta=0.1, \lambda=0.5$.

Table 2 Skin friction coefficient $f^{\prime \prime}(0)$. Wall temperature gradient $\theta^{\prime}(0)$. and temperature function $\theta(0)$ for different values of unsteady parameter $A$ and stretching parameter $\lambda$.

\begin{tabular}{|c|rrl|rrr|}
\hline & \multicolumn{3}{|c|}{$\lambda=0.5$} & \multicolumn{3}{|c|}{$\lambda=2.0$} \\
\hline$A$ & $f^{\prime \prime}(0)$ & $\theta^{\prime}(0)(\mathrm{VWT})$ & $\theta(0)(\mathrm{VHF})$ & $f^{\prime \prime}(0)$ & $\theta^{\prime}(0)(\mathrm{VWT})$ & $\theta(0)(\mathrm{VHF})$ \\
\hline 0.0 & -0.865010 & -0.839736 & 1.185007 & 2.221132 & -1.161893 & 0.866282 \\
0.2 & -0.903257 & -0.897433 & 1.109868 & 2.246273 & -1.196650 & 0.843498 \\
0.4 & -0.965240 & -0.946227 & 1.054195 & 2.270278 & -1.228909 & 0.824060 \\
0.5 & -1.074451 & -0.962418 & 1.037168 & 2.281756 & -1.244141 & 0.815445 \\
& & & & & & \\
\hline
\end{tabular}

Table 3 Wall temperature gradient $\theta^{\prime}(0)$ and temperature function $\theta(0)$ for different values of the parameters

\begin{tabular}{ccccccc}
\multicolumn{6}{c}{$\beta, A, \operatorname{Pr}, E c, N$, and $N r$} \\
\hline$\beta$ & $A$ & $\operatorname{Pr}$ & $E c$ & $N r$ & $\theta^{\prime}(0)($ VWT case $)$ & $\theta(0)$ (VHF case) \\
\hline 0.01 & 0.5 & 0.71 & 1 & 1 & -0.967132 & 1.031953 \\
0.05 & & & & & -0.965604 & 1.033679 \\
0.1 & & & & & -0.962418 & 1.037168 \\
0.1 & 0 & 0.71 & 1 & 1 & -0.675387 & 1.185007 \\
& 0.3 & & & & -0.745782 & 1.079694 \\
& 0.5 & & & & -0.779171 & 1.037168 \\
0.1 & 0.5 & 0.71 & 1 & 1 & -0.779171 & 1.037168 \\
& & 1.0 & & & -0.931270 & 0.875396 \\
& & 2.0 & & & -1.338263 & 0.627679 \\
0.1 & 0.5 & 0.71 & 0 & 1 & -1.537350 & 0.989002 \\
& & & 0.5 & & -1.405633 & 1.013085 \\
& & & 2.0 & & -1.010485 & 1.085333 \\
0.1 & 0.5 & 0.71 & 1 & 1 & -1.639629 & 1.037168 \\
& & & & 2 & -1.209158 & 1.270959 \\
& & & & 3 & -1.010485 & \\
\hline
\end{tabular}

\section{CONCLUSION}

The results are analyzed for the situation when stretching boundary is prescribed by non-isothermal variable wall temperature (VWT) and variable heat flux (VHF) which are varies quadratically with the flow directional coordinate $x$. The effect of various physical parameter like unsteady parameter $A$. Prandtl number
Pr, Eckret number $E c$ Hartmann number $M$, ratio of free stream velocity parameter to stretching sheet parameter $\lambda$ and thermal radiation parameter $N r$ on various momentum and heat transfer characteristics are obtained. Some of the interesting observations of this study are listed as follows;

The effect of magnetic parameter is to decrease the fluid and particle velocity when $\lambda<1$. 
The effect of magnetic parameter is to increase the fluid and particle velocity when $\lambda>1$, which is due to the formation of invert boundary layer.

Effect of unsteady parameter decrease the temperature profile of fluid and dust phases for both the cases of VWT and VHF when $\lambda<1$.

Effect of unsteady parameter increase the temperature profile of fluid and dust phases for both the cases of VWT and VHF $\lambda>1$.

At $\lambda=1.0$, there is no formation of a boundary layer.

Effect of thermal radiation parameter increases the temperature profile of fluid and dust phases for both the cases of VWT and VHF.

Always the rate of heat transfer $\theta^{\prime}(0)$ is negative and $\theta(0)$ is positive.

$\theta^{\prime}(0)$ and $\theta(0)$ increase with the increase of radiation parameter, fluid interaction parameter and Eckert number.

The increase in Prandtl number decreases the thermal boundary layer thickness.

If $A \leftarrow 0, \beta \rightarrow 0, N r \rightarrow 1, M \rightarrow 0$ and $N \rightarrow 0$ then our results coincides with the results of Pop et al. (2004) and Phool Singh et al. (2010) for various values of $\lambda$.

\section{ACKNOWLEDGMENTS}

We wish to express our thanks to University Grant commission New Delhi, for financial support to pursue this work under a Major Research Project F.No.36147/2008/(SR)/dated:26-03-2009).

\section{REFERENCES}

Abdul Aziz (2009). A similarity solution for laminar thermal boundary layer over a flat plate with a convective surface boundary condition, Com. Non. Sci. Numer. Simulat., 14, 1064-1068.

Ali, F.M., R. Nazar, N.M. Arifin and I. Pop, (2010). Unsteady flow and heat transfer past an axisymmetric permeable shrinking sheet with radiation effect, Int. J. Numer. Meth. Fluids.

Andersson, H.T., .J.B. Aareseth and B.S. Dandapat, (2000). Heat transfer in a liquid film on an unsteady stretching surface, Int. J. of Heat and Mass Transfer, 43, 69-74.

Brewster, M.Q. (1972). Thermal radiative transfer properties, John wiley and sons.

Carragher, P. and L.J. Crane, (1982), Heat transfer on a continuous stretching surface, Int. J. App. Math. Mech. (ZAMM), 62, 564-565.
Elbashbeshy, E.M.A. and D.A. Aldawody (2010). Effect of thermal radiation and magnetic field on unsteady mixed convection flow and heat transfer over a porous stretching surface, Int. J. nonlinear sciences, 9(4), 448-454.

Emad, M. Abo-Eladahad, M. A.El Aziz (2004), Blowing/suction effect on hydromagnetics heat transfer by mixed convection from an inclined continuously stretching surface with internal heat generation/absorption, Int. J. Therm. Sci., 43, 709719.

Grubka, L.J and K.M. Bobba (1985). Heat transfer characteristics of a continuous stretching surface with variable temperature, Int. J. of Heat and Mass Transfer, 107, 248-250.

Pop, I., S.R. Pop and T. Grosan (2004). Radiation Effect on flow near the stagnation point, Technische Mechanik, 2, 100-106.

Rafiuddin, S.Mustafa and M.V. Ramana Murthy (2008). Unsteady MHD memory flow with oscillatory suction, variable free stream and heat source, ARPN Journal of Engineering and Applied Sciences, 3, 17-24.

Saffman, P.G. (1962). On the stability of laminar flow of a dusty gas, Journal of Fluid Mechanics, 13,120128.

Sakiadis, B.C. (1961). Boundary layer behavior on continuous solid surface; I Boundary-layer equations for two-dimensional and axisymmetric flow, A.I.Ch.E.J, 7, 26-28.

Sharidan, S., T. Mahmood and I. Pop (2006). Similarity solutions for the unsteady boundary layer flow and heat transfer due to stretching sheet, Int. J. Appl. Mechanics and engineering, 11(3), 647-654.

Sharma, P.R. and G. Singh (2009). Effects of variable thermal conductivity and heat source/ sink on MHD flow near a stagnation point on a linearly stretching sheet, J. of App. Fluid Mech., 2, 13-21.

Shercliff, J.A. (1965). A text book of magnetohy drodynamics, Pergamon press, London.

Singh, Ph., A. Jangid, N.S. Tomer and D. Sinha, (2010). Effects of thermal radiation and magnetic field on unsteady stretching permeable sheet in presence of free stream velocity, Int. J. of Information and Mathematical Sciences, 03, 160-166. 
B. J. Gireesha et al. / JAFM, Vol. 7, No. 1, pp. 15-24, 2014.

Subhas, A. M. and N. Mahesha (2008). Heat transfer in MHD visco-elastic fluid flow over a stretching sheet with variable thermal conductivity, nonuniform heat source and radiation, Applied mathematical modeling, 32, 1965-1983.

Tsou, F.K., E.M. Sparrow, R.J. Glodstein (1967). Flow and heat transfer in the boundary layer on a continuous moving surface, Int. J. Heat Mass Transfer, 10, 219-235.
Vajravelu, K. and J. Nayfeh (1992). Hydromagnetic flow of a dusty fluid over a stretching sheet, Int. J. non-linear Mechanics, 27(6), 937-945. 